\title{
Redesain Meja Cetakan Mesin 3D Printer Berbasis Fused Deposition Modelling
}

\author{
Sally Cahyati ${ }^{1{ }^{*}}$, Dhifan Putra ${ }^{2)^{\star}}$ \\ ${ }^{1,2)}$ Jurusan Teknik Mesin Universitas Trisakti, Kampus Universitas Trisakti
}

Naskah diterima 27 Agustus 2019; direvisi 22 September 2019; disetujui 28 Oktober 2019 doi: https://doi.org/10.24843/JEM.2019.v12.i02.p09

\begin{abstract}
Abstrak
Mesin 3D printer adalah mesin pembuat suatu model 3D. Metode mesin 3D printer yang digunakan pada Fakultas Teknologi Industri Universitas Trisakti adalah metode FDM (Fused Deposition Modelling). Diketahui adanya ketidak stabilan pada meja cetakan mesin 3D printer pada saat proses produksi dilakukan. Ketidak stabilan meja cetakan mesin 3D printer, menyebabkan tidak maksimalnya produk yang dihasilkan. Terdapat perbedaan antara hasil produk dengan bentuk produk yang telah di desain sebelumnya. Setelah diteliti lebih lanjut, ketidakrataan pada meja disebabkan pada pengaturan meja cetakan yang kurang sesuai. Hasil dari redesain dapat menstabilkan meja cetakan dan memudahkan untuk melakukan kalibrasi dan pengaturan pada meja cetakan mesin 3D printer. Hal ini terbukti ketelitian dimensi produk hasil cetakan yang meningkat dari penyimpangan terbesar $0,037 \mathrm{~mm}$ menjadi $0,069 \mathrm{~mm}$, yang diukur dengan proyektor profil yang mempunyai kecermatan 1 mikrometer.
\end{abstract}

Kata Kunci: Redesain, FDM, Meja, Mesin, Kestabilan, Model, 3D printer

\begin{abstract}
3D Printer Machine is a 3D shaped model making machine. The method of 3D printer machine used by the faculty OF Industrial Technology of Trisakti University is FDM (Fused Deposition Modelling) method. There is known unevenness on the build plate of 3D printer machines during the production process. The unevenness that appears on the objects makes the build plate used by the 3D printer engine unstable. This causes the product to be produced not maximal. There is a difference in shape between product results and previous product design. After further investigation, the unevenness of the table was caused by the improper arrangement of the printed table. The results of the redesign will stabilize the print table and make it easier to calibrate and adjust the print table of the 3D printer machine. This proven that precision of product dimension increase from $0,037 \mathrm{~mm}$ deviation to $0,004 \mathrm{~mm}$, its measured with a profile projector has 1 micrometer resolution.
\end{abstract}

Keywords: Re-design, FDM, table, machine, flatness, Model, 3D printer

\section{Pendahuluan}

Dunia industri terus mengalami perkembangan, terutama pada industri yang bergerak di bidang manufaktur [1]. Banyaknya inovasi-inovasi baru membuat dunia industri semakin berkembang pesat. Pada revolusi 4.0 salah satu teknologi pendukung yang digunakan adalah layer manufacturing atau rapid peorotyping. Mesin rapid prototyping pada intinya mencetak bentuk fisik dari sebuah desain produk 2 dimensi menjadi 3 dimensi [2]. Teknologi layer manufacturing yang diimplementasikan pada mesin 3D printer ini adalah sebuah teknologi yang dapat menghasilkan sebuah produk custom dengan waktu yang singkat. Mesin 3D printer yang digunakan ini bernozel ganda karena, hasil dari produk mesin 3D printer nozel ganda dapat menghasilkan variasi warna dan nozel ganda lebih efisien dibanding menggunakan satu nozel [3].

3D printing atau dikenal juga sebagai additive layer manufacturing adalah sebuah proses membuat objek 3 dimensi yang menampilkan data dalam bentuk cetakan [4]. Desain yang dibuat untuk menghasilkan objek 3 dimensi sebelum proses pencetakan menggunakan mesin 3D printer harus dilalui dengan mendesain produk menggunakan berbagai macam software CAE (Computer Aided Engineering). Proses 3D printing dapat dilakukan dengan menggunakan 3D Laser Scanning, benda yang telah dilakukan scanning kemudian di cetak melalui mesin 3D printer tanpa harus melalui proses desain. Sehingga benda yang sudah jadi dapat di tiru dan sesuai dengan hasil yang telah dilakukan proses scanning dengan mesin 3D Laser Scanning [5].

Salah satu komponen mesin 3D printer yang sangat mempengaruhi kualitas produksi produk adalah meja cetakan. Ada dua kondisi meja cetakan yang harus diperhatikan yaitu keseimbangan meja dan sistem pengaturan ketinggian meja. Sistem pengaturan ketinggian ini adalah untuk memecahkan permasalahan waktu kalibrasi meja saat akan digunakan.

Penelitian ini membahas pengaruh redesain meja cetakan mesin 3D printer terhadap benda uji yang di cetak. Benda uji yang di cetak memiliki tinggi yang berbeda terhadap ukuran benda uji untuk mengetahui perbandingan hasil cetakan terhadap model 3D CAD. 


\section{Metode Penelitian}

\subsection{Bahan}

Bahan yang digunakan pada penelitian ini adalah filament PLA dengan diameter $1.75 \mathrm{~mm}$. Filament ini dipilih karena memiliki hasil yang lebih kuat dan rapih.

2.2. Alat Penelitian

Alat yang digunakan pada penelitian ini adalah:

1. Mesin 3D printer MakerGear M2 nozel ganda berbasis FDM dengan meja cetakan sebelum dilakukan redesain.

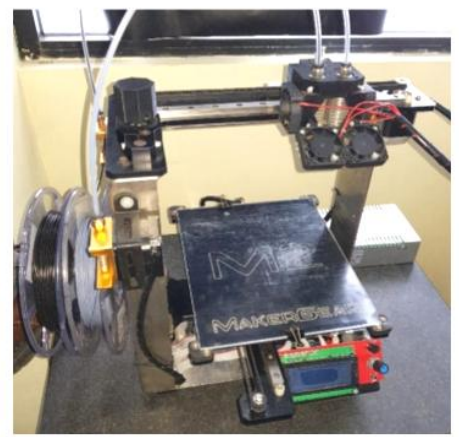

Gambar 1. Mesin 3D Printer Sebelum Redesain

2. Proyektor Profil PJ300 Mitutoyo digunakan untuk mengukur dimensi (lebar dan tinggi) benda uji yang dicetak mesin 3D printer. Proyektor Profil ini memiliki kecermatan 1 micrometer.

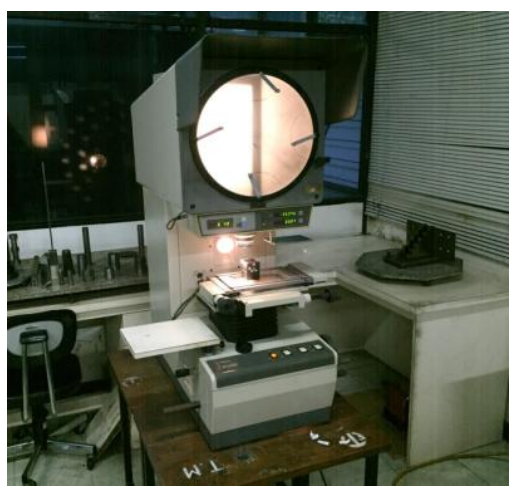

Gambar 2. Proyektor Profil

\subsection{Diagram Alir Penelitian}

Penelitian yang dilakukan akan mengacu kepada langkah-langkah dalam diagram alir yang ada pada Gambar 3.

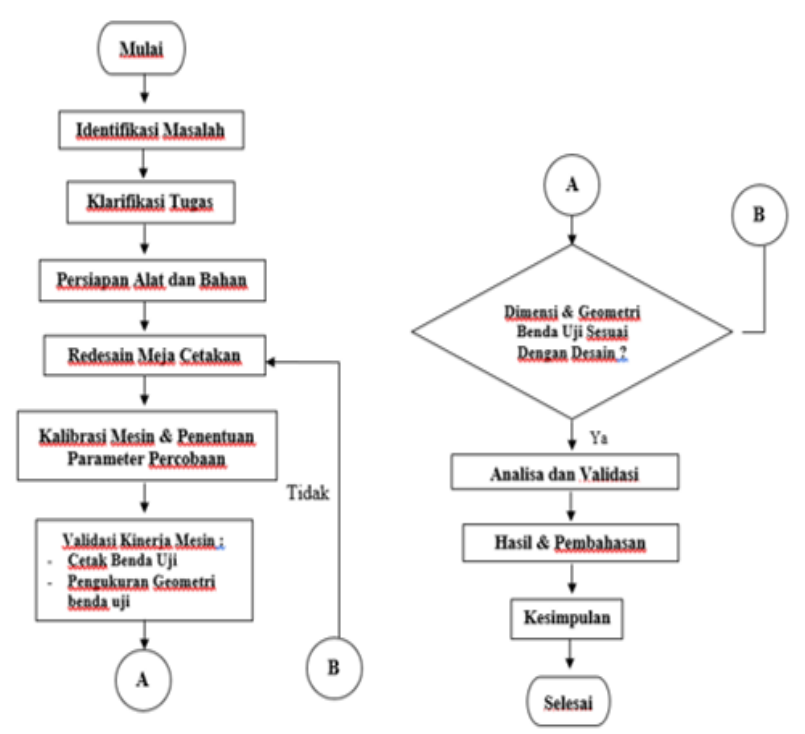

Gambar 3. Diagram Alir

\subsection{Proses Redesain Meja Cetakan}

Proses redesain meja cetakan dilakukan setelah pencetakan benda uji dengan desain awal. Benda uji dicetak terlebih dahulu sebelum proses redesain dikarenakan untuk mengetahui hasil perbandingan benda uji sebelum redesain dengan benda uji setelah redesain. Redesain meja cetakan dibuat dengan menggunakan software Autodesk Fusion 360. Redesain meja cetakan dapat dilihat pada Gambar 3. Setelah meja cetakan di redesain maka dibuat gambar kerja untuk dilanjutkan proses pembuatan komponen meja cetakan gambar kerja meja cetakan dapat dilihat pada Gambar 4 dan 5.

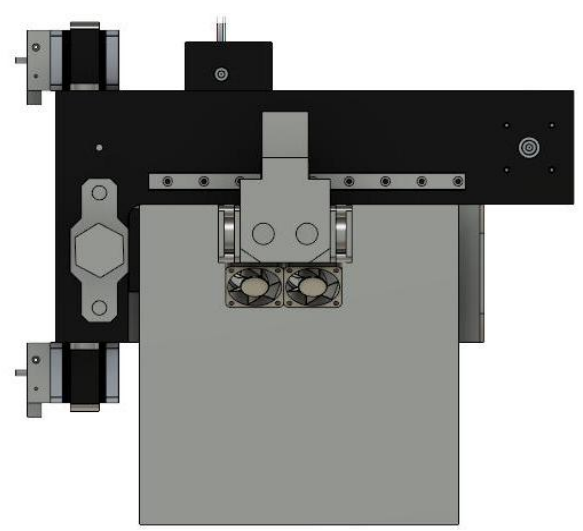

Gambar 3. Redesain Meja Cetakan

Redesain meja cetakan dilakukan untuk mengurangi ketidakstabilan pada meja cetakan. Pada saat dilakukannya pencetakan benda uji sebelum dilakukan redesain, memiliki kesulitan saat melakukan pengaturan meja cetakan, sehingga jarak nozel terhadap meja cetakan selalu berubah ketika proses pencetakan dan menyebabkan kegagalan produk.

Pada Gambar 4. dijelaskan gambar kerja komponen mesin 3D printer yang telah di desain, untuk proses pembuatan komponen. 


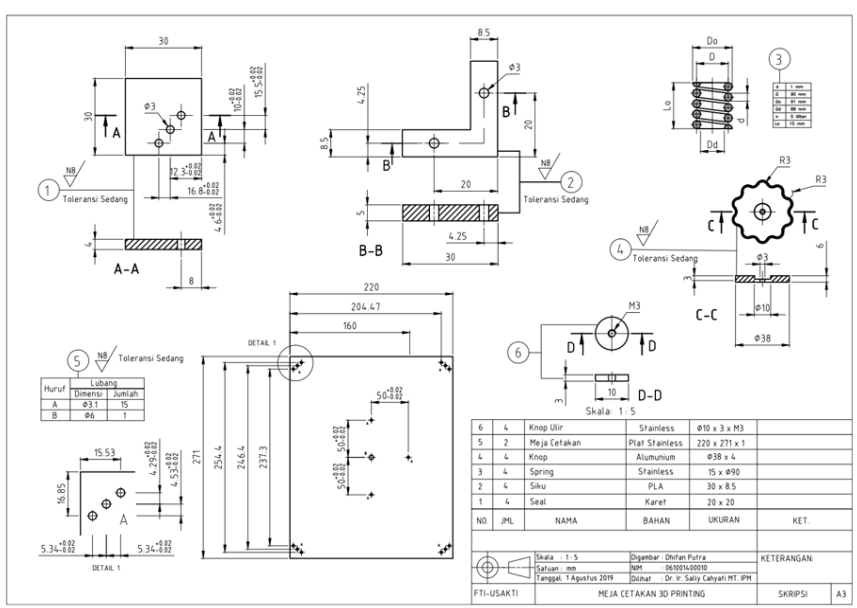

Gambar 4. Gambar Kerja Meja Cetakan

Pada Gambar 5. Dijelaskan assembly dari komponen yang telah dirancang, untuk di aplikasikan pada meja cetakan mesin 3D printer MakerGear.

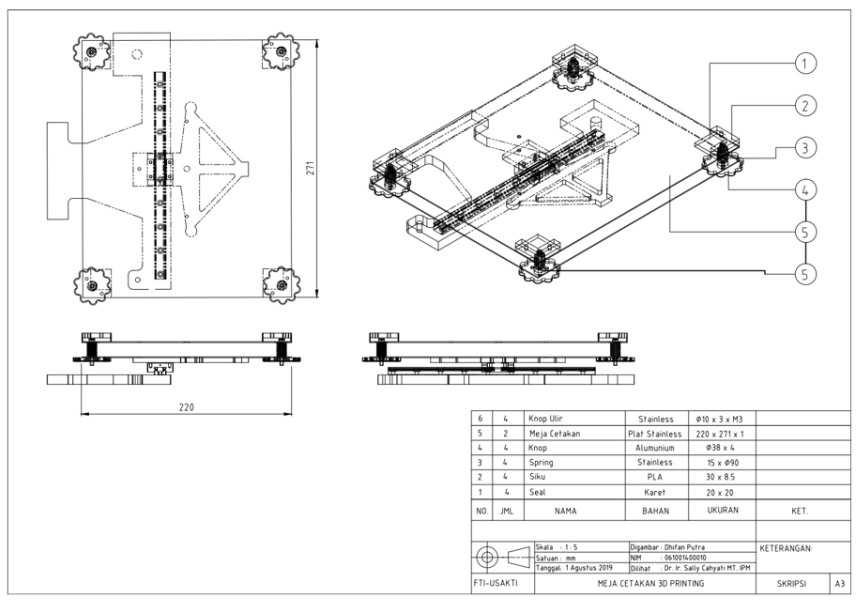

Gambar 5. Gambar Kerja Meja Cetakan

\subsection{Pencetakan Benda Uji}

Pencetakan benda uji dilakukan dengan meja cetakan sebelum redesain dan dengan meja cetakan setelah redesain. Benda uji yang dicetak menggunakan dua warna filament yang berbeda.

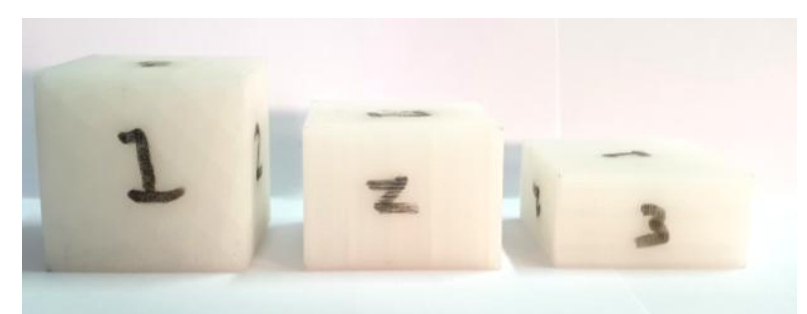

Gambar 6. Hasil benda uji Sebelum Redesain

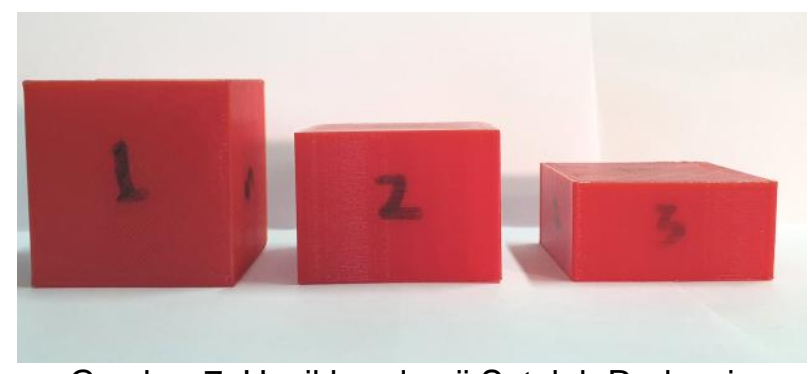

Gambar 7. Hasil benda uji Setelah Redesain

\subsection{Pengukuran Ketelitian Dimensi benda uji}

Pengukuran dilakukan setelah benda uji dicetak dengan perbedaan proses pencetakan meja cetakan sebelum di redesain dan meja cetakan setelah di redesain. Pengukuran benda uji yang dilakukan dengan mengukur lebar, tinggi, dan kemiringan benda uji. Pengukuran ini bertujuan untuk mengetahui simpangan dari benda uji.

\section{Hasil dan Pembahasan}

\subsection{Analisa benda uji}

Setelah dilakukan pengukuran dengan proyektor profil, data yang dihasilkan kemudian dibuat grafik. Gambar 8. Memperlihatkan hasil pengukuran lebar benda uji sebelum redesain dan lebar benda uji setelah redesain. Ukuran lebar yang diambil dari benda uji yang mempunyai ketinggian yang berbeda yaitu dengan tinggi $40 \mathrm{~mm}, 30 \mathrm{~mm}$, dan $20 \mathrm{~mm}$. Grafik tersebut memperlihatkan bahwa terjadi peningkatan ketelitian dari penyimpangan maksimal sebesar 40,443 $\mathrm{mm}$ menjadi 40,155 $\mathrm{mm}$.

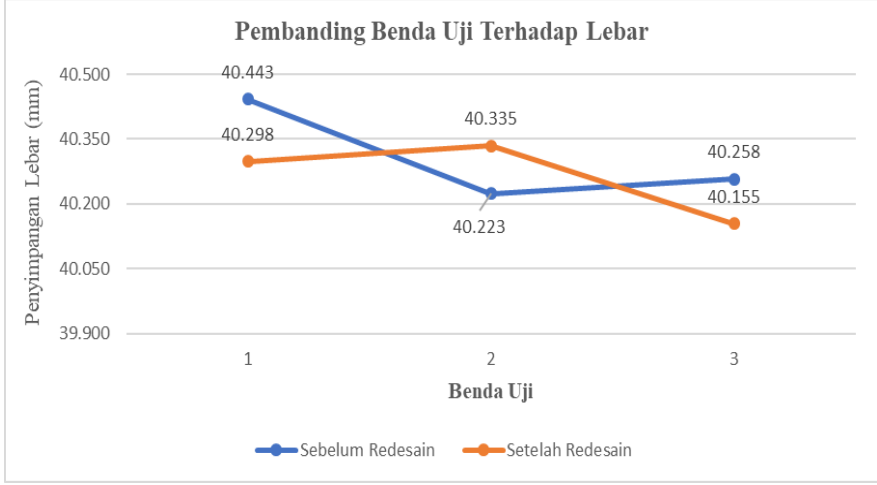

Gambar 8. Grafik Pembandingan Lebar

Pada Gambar 9. grafik tersebut memperlihatkan pada benda uji dengan tinggi $40 \mathrm{~mm}$ sebelum redesain memiliki ketilitian 40,295 mm dan pada benda uji setelah redesain memiliki ketelitian $40,269 \mathrm{~mm}$. Pada benda uji dengan tinggi $30 \mathrm{~mm}$ sebelum redesain memiliki ketelitian $30,095 \mathrm{~mm}$ dan pada benda uji setelah redesain memiliki ketelitian $30,219 \mathrm{~mm}$. Pada benda uji dengan tinggi $20 \mathrm{~mm}$ sebelum redesain memiliki ketelitian 20,271 dan pada benda uji setelah redesain memiliki ketelitian $20,158 \mathrm{~mm}$.

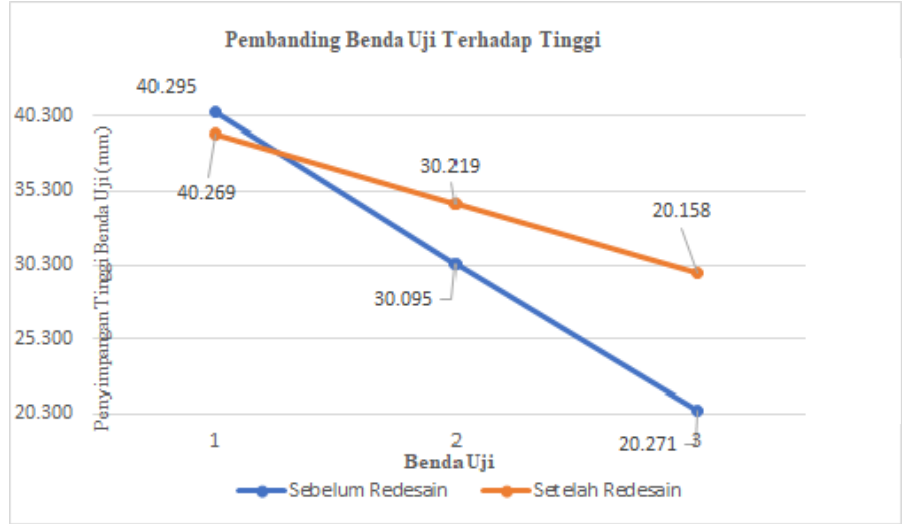

Gambar 9. Grafik Pembandingan Tinggi 
Dapat diamati dari hasil pengukuran benda uji perbandingan dari ke tiga benda uji sebelum redesain dengan benda uji setelah redesain memiliki nilai penyimpangan lebih kecil dibandingkan benda uji sebelum redesain. Setelah benda uji dilakukan Analisa pembandingan dilanjutkan dengan validasi produk untuk mengetahui penyimpangan yang terjadi pada benda uji.

\subsection{Validasi benda uji}

Setelah dilakukan analisa ketelitian dimensi benda uji kemudian, divalidasi untuk mengetahui simpangan dari benda uji yang telah diukur. Hasil simpangan dapat dilihat pada Tabel 1 dan Tabel 2. Pada tabel dijelaskan bahwa $\mathrm{X}$ adalah lebar, $\mathrm{Y}$ adalah Tinggi, dan $\alpha$ adalah kemiringan.

Validasi mesin dilakukan untuk mencari penyimpangan yang terjadi pada benda uji, dengan menghitung nilai varians, standar deviasi, dan ketidakpastian. Untuk mncari penyimpangan harus dilalui perhitungan dengan menggunakan rumus diantaranya:

\section{Menghitung Rata-rata}

$$
\bar{X}=\frac{X_{1}+X_{2}+\ldots+X_{n}}{n}=\frac{1}{n} \sum_{i=1}^{n} X_{i}
$$

2. Menghitung Varians

$$
\begin{aligned}
\mathrm{S} & =\frac{\left(X_{1}-\bar{X}\right)^{2}+\left(X_{2}-\bar{X}\right)^{2}+\ldots .+\left(X_{n}-\bar{X}\right)^{2}}{n-1} \\
& =\frac{1}{n-1} \sum_{i=1}^{n}\left(X_{1}-\bar{X}\right)^{2} \quad \ldots \ldots \ldots \ldots \ldots
\end{aligned}
$$

3. Menghitung Ketidakpastian

$$
\mathrm{U}_{\mathrm{A}}=S(\bar{X})=\frac{S}{\sqrt{n}}
$$

Tabel 1. Penyimpangan Benda Uji Sebelum Redesain

\begin{tabular}{cccccc}
\multicolumn{2}{c}{ Varians $(\mathrm{mm})$} & \multicolumn{2}{c}{ Standar Deviasi $(\mathrm{mm})$} & \multicolumn{2}{c}{ Ketidakpastian $(\mathrm{mm})$} \\
\hline $\mathrm{X}$ & $\mathrm{Y}$ & $\mathrm{X}$ & $\mathrm{Y}$ & $\mathrm{X}$ & $\mathrm{Y}$ \\
\hline 0.003 & 0.016 & 0.058 & 0.125 & 0.026 & 0.037 \\
\hline 0.028 & 0.002 & 0.168 & 0.045 & 0.038 & 0.004 \\
\hline 0.003 & 0.001 & 0.054 & 0.024 & 0.014 & 0.006 \\
\hline
\end{tabular}

Dari Tabel 1. dapat dilihat benda uji sebelum dilakukan redesain meja cetakan ini memiliki angka penyimpangan paling tinggi adalah $X=0,038 \mathrm{~mm}$ dan $\mathrm{Y}=0,037 \mathrm{~mm}$,

Tabel 2. Penyimpangan Benda Uji Setelah Redesain

\begin{tabular}{cccccc}
\hline \multicolumn{2}{c}{ Varians $(\mathrm{mm})$} & \multicolumn{2}{c}{ Standar Deviasi (mm) } & \multicolumn{2}{c}{ Ketidakpastian (mm) } \\
\hline $\mathrm{X}$ & $\mathrm{Y}$ & $\mathrm{X}$ & $\mathrm{Y}$ & $\mathrm{X}$ & $\mathrm{Y}$ \\
\hline 0.003 & 0.003 & 0.057 & 0.054 & 0.017 & 0.015 \\
\hline 0.001 & 0.005 & 0.032 & 0.069 & 0.011 & 0.015 \\
\hline 0.001 & 0.002 & 0.031 & 0.045 & 0.005 & 0.007 \\
\hline
\end{tabular}

Dari Tabel 2. dapat dilihat benda uji sebelum dilakukan modifikasi meja cetakan ini memiliki angka penyimpangan paling tinggi adalah $X=0,017 \mathrm{~mm}$, dan $\mathrm{Y}=0,015 \mathrm{~mm}$.

Setelah benda uji dilakukan validasi dengan membandingkan model 3D CAD-nya. Benda uji yang lebih mendekati dimensi dari model 3D CAD terdapat pada benda uji setelah dilakukan redesain. Hasil dari validasi ini meja cetakan setelah di redesain memiliki penyimpangan dari benda uji lebih rendah dibandingkan benda uji sebelum di redesain dan memungkinkan mesin ini untuk dipakai mencetak suatu produk karena, mesin ini memiliki penyimpangan yang paling tinggi pada mesin $3 \mathrm{D}$ printer sebelum redesain meja cetakan adalah $\mathrm{X}=0,038 \mathrm{~mm}$, dan $\mathrm{Y}=$ $0,037 \mathrm{~mm}$.

Hasil perhitungan ketidakpastian dari ke enam benda uji sebelum redesain dan setelah redesain meja cetakan menyatakan bahwa, meja cetakan setelah redesain pada mesin 3D printer ini menghasilkan perbaikan yang signifikan pada benda uji yang di cetak. Hasil perhitungan ke enam benda uji mesin 3D printer ini mempunyai penyimpangan tertinggi yang dicapai oleh mesin 3D printer ini adalah $X=0,017 \mathrm{~mm}$, dan $Y=0,015 \mathrm{~mm}$. Peningkatan ketelitian dimensi lebar benda uji meningkat sebanyak $55 \%$ dan pada ketelitian dimensi tinggi benda uji meningkat sebanyak $61 \%$.

\section{Simpulan}

Meja mesin 3D printer hasil redesain menunjukan adanya pengaruh terhadap peningkatan ketelitian dimensi produk cetak. Peningkatan ketelitian dimensi lebar benda uji meningkat sebanyak $55 \%$ dan pada ketelitian dimensi tinggi benda uji meningkat sebanyak $61 \%$. Dengan demikian meja cetakan hasil redesain valid untuk digunakan.

\section{Daftar Pustaka}

[1] M. Dahlan, "Rancang Bangun Printer 3D Menggunakan Kontroller Arduino Mega 2560," Pros. SNATIF, vol. 4, pp. 105-110, 2017.

[2] S. Cahyati, B. Satriawan, J. Teknik, M. Fakultas, T. Industri, and U. Trisakti, "Ketelitian Dimensi Produk Hasil Proses Modifikasi Mesin Fdm Dual Extruder," pp. 1-7, 2019.

[3] S. Cahyati et al., "Analisa Kekuatan Kerangka Penopang Ekstruder Modifikasi Mesin 3d Printer Nozel Tunggal Menjadi Nozel Ganda," pp. 1-7, 2019.

[4] I. Gibson, D. Rosen, and B. Stucker, Additive manufacturing technologies: $3 D$ printing, rapid prototyping, and direct digital manufacturing, second edition. 2015.

[5] S. Cahyati and A. Rahmat, "Kualifikasi Alat 3D Laser Scanner Terintegrasi Menggunakan Tiga Tipe Smartphone Sebagai Alat Input," Pros. Semin. Nas. Pakar, vol. 1, no. 1, pp. 1-29.11.29.7, 2019. 